\title{
The Case Of The Curious And \\ The Confident - The Untold Story \\ Of Changing Teacher Attitudes \\ To E-Learning And "Technology In \\ Action" In The FE Sector
}

Nigel Ecclesfield

Learning and Skills Improvement Service

Geoff Rebbeck

Institute for Learning

Fred Garnett

London Knowledge Lab

\section{Abstract}

This paper attempts to highlight findings from the recent LSIS (Learning and Skills Improvement Service) survey into practitioner attitudes to technology. We presented the initial findings of a research project funded by LSIS to the Greenwich e-learning conference in July 2011.

A number of interesting insights can be identified concerning both the methodology used and the results obtained. In terms of the methodology we believe that the more qualitative approach used, which we describe as examining 'technology in action', can provide deeper systematic insights into practitioner uses of technology for learning, as well as indicating individual practice. Secondly, as a consequence of this approach, we have also unearthed some original insights into the use of technology for learning in colleges. Additionally, the almost 'learning analytics' approach to gathering survey data (Ecclesfield and Smith, 2011), also allowed us to create individual narratives of professional practice.

As a consequence we will discuss the following issues; a new methodological approach using new tools and survey instruments, a wider ranging curiosity-driven use of technology for learning in the practitioner, highlighting approaches reflecting personal development of practice, which extends the concept of both staff and professional development. Overall our findings reflect a new professional confidence in using technology in colleges, which emerges from individual practitioner's personal curiosity in how technology might be used to help students learn. 


\section{The background to the research}

In 2008-9 discussions between the authors developed as a result of our joint involvement in work on institutional self-assessment tools as we felt that current surveys were not capturing the range and scope of practitioner use of technology in the further education (FE) and skills sector. One of the authors (Geoff Rebbeck) proposed an alternative model of exploring technology use and implementation, which involved the use of survey questions which explored respondents' attitudes to technology and specifically their use of 'technology in action' with a view to identifying from measures of attitude, those individuals who might be predisposed, as a result of their attitudes, to further exploration and engagement with technology and provide a more receptive audience for technology training and implementation. Respondents were asked to rate their feelings about their use of technology cited in the questions, rather than state what technologies they used.

Emerging from this study was a prototype survey instrument and indications that the methodology used could identify characteristic profiles of organisational and departmental attitudes to technology that were consistent with the findings of the national surveys in terms of identifying those who had no knowledge of or were disengaged from the use of technology in their practices as well as those who were more confident and capable in their practices.

An opportunity to extend the work came in early 2011 which resulted in the work reported here. In scaling up the methods, a decision was made to use an online survey to gather, initially, 200+ plus responses were needed to test the method and organise the data for initial analysis. A key decision was to move away from a single comment box at the end of the survey to providing a free text box with each question, although no respondent was required to enter comments in these boxes. From the survey tool (Survey Monkey), we were able to download the quantitative data and carry out a conventional analysis using Excel and also download the free text responses which were analysed using the tools and methodology described in Morris and Ecclesfield (2011) to explore themes emerging from responses at provider level, in subject groupings and the self-assessment classifications produced by individual respondents.

Subsequently we found that linking individual responses to questions together generated coherent narratives of practice that provided insight into practitioner practices as well as attitudes to technology - examples of these are presented below. Now that the data includes $700+$ narratives we have the detailed account of 'technology in action' we have been seeking. The study approached 1,000 individuals of whom 815 have responded and we are confident that the sample we achieved is broadly representative of the range of opinions and capability in the institutions participating in phases one and two of this work. Phase three seeks to provide a more representative sample of practitioners across the sector as a whole.

\section{The research}

815 practitioners drawn from providers of adult and community learning, work-based learning and FE colleges completed an online survey of their attitudes to technologies in use within the sector. The survey consisted of nineteen questions in six sections:

About yourself and the context of your work

VLE, learning platforms and texting

Online discussions

Using different media and formats in my work 


\section{What I do}

Personal development, collaboration and reflection, which included a self-rating question using the typology devised by the project team.

Each question was presented in the form of a self-rating scale of 'responses in action' consisting of seven options ranging from, 'I don't know about this' to 'normative' where the technology is fully integrated into the work of the practitioner. In addition, respondents were given the opportunity to comment on their responses or the questions themselves in a large free-text box after each question.

The response rate to the survey was $82 \%$ of those nominated $(1,000)$, perhaps because we offered a USB drive to participants. We gathered large amounts of free text which was used by respondents to justify or reflect on their responses. Despite our making answers to all questions optional, we were both surprised and gratified by the volume of the responses we received. Respondents were offered their own data and a small incentive in return for participation.

A full account of the research, the methodology, detailed findings and the data can be found on the LSIS research pages on the excellence gateway (LSIS, 2011), while this paper explores the implications of those findings in the context of a series of questions raised for us by the first phase of the study and our subsequent analyses of 14,700 responses to the questions in the survey and the 250,000 words of free text responses. The key findings are described to set the context for the discussion and the authors welcome further exploration of this work with colleagues.

\section{The analysis}

We have utilised research findings and models drawn from the Learner-Generated Contexts group (Luckin et al., 2010) and the Open Context model of learning, (Mitra and Dangwal, 2010) on self-organised and selfmediated learning environments (SOLEs and SOMEs), Anderson's model of open scholarship (Anderson, 2009), Wesch's work on learner engagement with planning, delivery and assessment of learning activities (Wesch, 2011) and Haythornthwaite's explorations of the influence of networks on learning and the nature of collaboration (Haythornthwaite 2010). The basis for the analysis here has been our shared work on what we call 'the craft of teaching' developed at the iPED conferences and with the Working Lives Project and on our views of research and scholarship seen in the proceedings for ALT-C 2011 (Garnett and Ecclesfield, 2011).

We are also seeking to address the issues emerging from recent challenges to teaching practices which appears to seek the replacement of face-to-face teaching by greater use of instructional technology, based on the experience of learndirect in the UK and on corporate training programmes championed by, among others, Alison Rossett in the USA (Rossett and Schafer, 2010). Within the present political and economic climate in the UK and overseas, the focus on digital skills has become linked to other strands of thinking that focus on the economics of learning and the promise, as yet unrealised, of using technology in a way that reduces the cost of learning by replacing the two most costly elements of provision, namely staffing and estate costs.

From this exploration we will present a view of practitioner use of technology that shows transformation of practice in the FE and skills sector through diversification of approaches and how practitioners as users of technology in their personal lives, are viewing the use of technology in their teaching and engagement with learners. 


\section{Key findings}

\section{"The enquiring mind"}

From the structured range of responses available, from 'don't know' to 'independent', there was a clear pattern of respondents demonstrating 'an enquiring mind' in their approach to facing new technology. These were the responses that indicated either a willingness to explore different uses of technology or where it was part of their practice. It is arguable that this demonstrates a shift in what might be called the e-learning journey in comparison with five years ago where teachers were expected to be relatively passive and wait for direction and instruction, seeing technology use as a method of standardising approaches to teaching. Our survey suggests that teachers now prefer a more self-managed approach. We can talk in terms of an improving confidence in investigating and adapting technology for use in particular contexts and all the benefits that can bring to progress through collaborative activity.

\section{The opportunity for wider influence}

The opportunity for teachers to consult and exchange ideas outside of college is still underdeveloped because it is all contextualised with in-college experience. However, the similarities in mindsets and approach shown in the responses to the survey suggest that efforts to support this process of crossorganisational communication and collaboration would be an extremely fruitful enterprise were it to happen more frequently. Petty (2006) suggests that the greatest change in teaching practice occurs where teachers exchange ideas and our research supports this in identifying a common approach to assimilating the new. The narratives support the view that teachers are more conscious of the value of technology to the sector rather than of the value to self and personal development. It also shows how much desire there is to communicate and share ideas with others.

It is clear that the use of learning platforms is now normative, being embedded in nearly every FE college. It is perhaps a good example of high impact technology demonstrated by its invisibility. The learning platform of choice in over $75 \%$ of colleges is Moodle which offers the widest opportunity for individuals and providers to configure the application to meeting specific requirement needs. It is arguable that the speed of adoption of Moodle since 2006, following the national scheme to purchase of commercial platforms in 2004-6, has been hastened by the ability of practitioners to contextualise its use for specific groups and purposes and, in some cases, engage learners as contributors to the content and configuration of Moodle installations.

\section{Web 2.0 technologies}

Social media technologies are understood in terms of personal use but not fully in teaching terms. Texting for example is a familiar technology but not understood as an effective tool in a teaching and learning situation.

\section{The diversity of technology in action}

Our research offers a challenge to the perceived wisdom that technology is a force for centralising good practice, where benefits accrued from one experience can be replicated easily to others. Rather than technology becoming a force for unification and centrality, it is taking teachers and their learners into unique learning situations that work in terms of good teaching and learning that teachers are now able to articulate more clearly. It would be interesting to explore the degree to which technology is allowing teachers to diversify their approach and practice of curriculum design and delivery, challenging the 
organisational culture of central, settled methods of deliverables, based on relatively few, well defined 'inputs' and certainties of practice.

\section{The emotive and narrative responses to technology in action.}

Asking people how they feel about 'technology in action' instead of 'what they know' appears to provoke a need in respondents to explain or justify the reaction. Consequently this survey has a much higher than usual level of free responses. The underlying findings of this research lead to a better understanding of the notion of 'confidence' as we believe this to be a key to the successful assimilation of technology into learning. The markedly positive response from the exploring or enquiring mind suggests that teachers, on the whole, believe that the risks inherent in exploring new technologies to improve teaching and learning are now considered to be worthwhile rather than something to be shunned or be undertaken under the direction of an expert. It can be argued that these results demonstrate that practitioners are now confident enough to use technology for their own professional purposes and integrate this into their personal 'ethic of care' (Jephcote, Salisbury and Rees, 2008).

The principal gain from the survey methods adopted has been the rich data obtained from the free text responses, which we have been able to analyse in two ways:

1) By constructing user narratives from the free text responses, which aggregate the responses to individual questions

2) Through the use of text analysis to identify key/common themes emerging from the $800+$ responses recorded in the free text boxes. (See diagram on page 50)

We are currently exploring differentiated narratives drawn from subject areas and from the response categories in the questions e.g. the 'don't knows' and the 'collaborative users' and we will, in time, be able to explore the narratives at provider level as a large proportion of the sample providers have 50 or more respondents participating in the study.

The thematic analysis of our current sample shows that the six most often occurring themes are: students, teaching, colleagues, Moodle, texting and blog.

The interest lies in what we are calling the 'knowledge signature' (see Morris and Ecclesfield 2011, pp. 245-6) of these responses, which includes the second and third level concepts associated with these key terms.

It is our ability to compare the different signatures of different subject groups, provider profiles and selfclassification categories that gives us the option to widen our analysis and build on the profiles mapped through the analysis of individual responses to the survey questions.

\section{Locating the digital practitioner}

Our research provides much evidence for the view of the maturing of FE sector practitioner attitudes in England to the use of technology and that this maturity is characterised by confidence in the use of technology across a widening range of applications and equipment. The original premise of inexperienced teachers requiring process training in how technology works could now give way to an expectation of technology use by confident teachers who want support and collaboration to examine the use of different technologies in good teaching and learning practice, with students and their learning experience at the heart of professional concerns. Teachers have developed the ability 


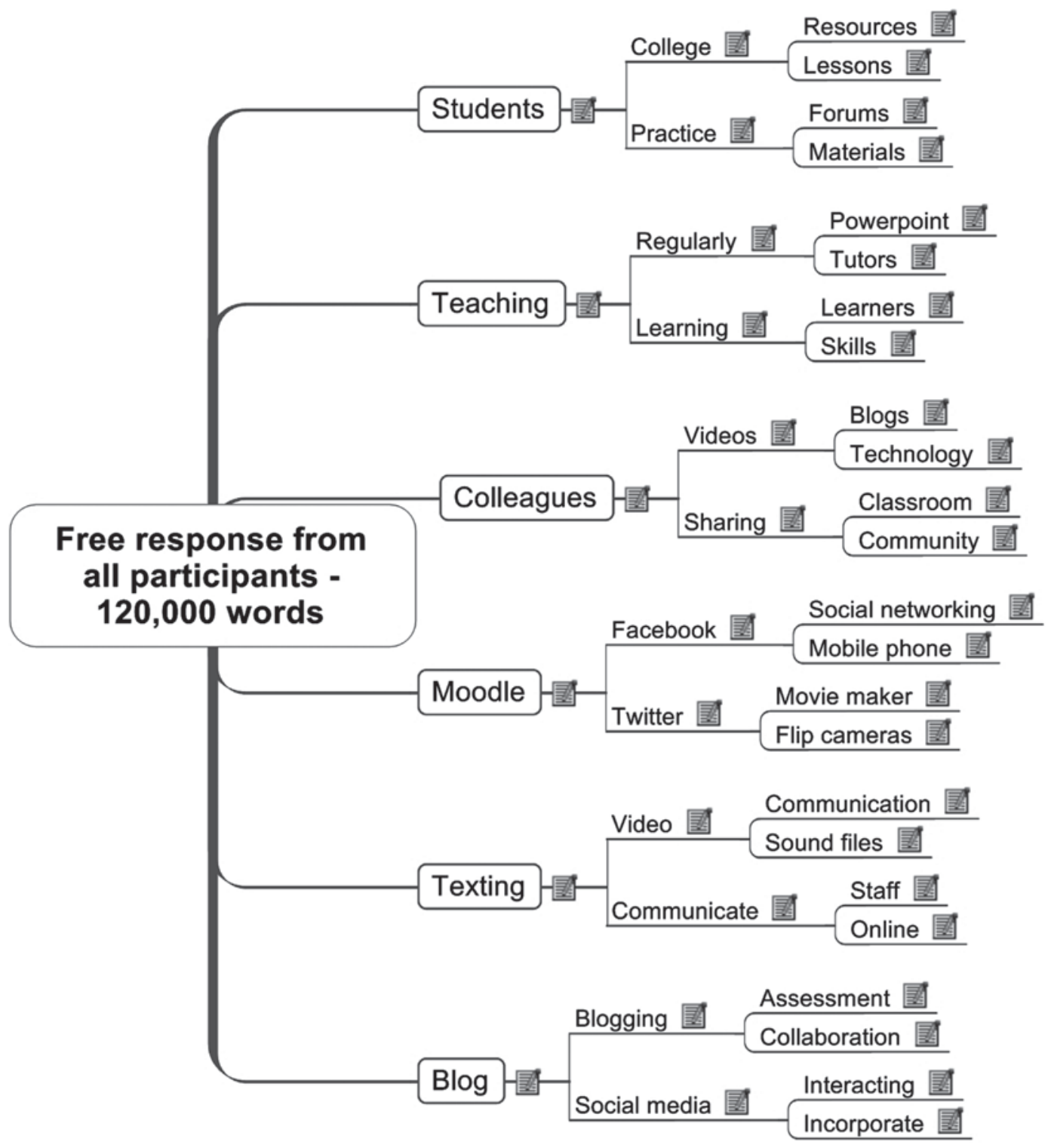

Figure 1 Analysis of key themes emerging from the free text produced by the respondents

to navigate their way through a range of technology options and uses with this professional focus on teaching and learning, which is alive to the needs of colleagues and their work contexts.

Furthermore considering the 'normalisation' of many technologies into learning practice as evidenced in the survey e.g. word processing, which is only referenced in ten instances, it is possible that we may have been deceived, in the past, in our search for the impact of technology, expecting it to be physically manifested and overt in everything teachers do. It could be that successful impact is evidenced by the opposite; technology use being one element in many artfully constructed student-centred 
learning experiences that are part of everyday practice, such that the technology is not really seen nor acknowledged, simply being used when deemed appropriate for learning as planned.

This appears to be the case with the now ubiquitous use of Moodle VLEs, for example. Perhaps only new or troublesome or unsatisfactory technologies with little immediate application to practice remain on the surface and open to view, and thus to questioning? It may be that the greatest impact of technology actually occurs where its use is not seen, nor recognised in framing immediate survey responses, but when that use emerges through prompts that promote reflection on practice, as indicated in our findings. This view has some support in recent literature on e-learning such as Haythornthwaite and Andrews (2011, p. 39) where they quote Bruce and Hogan who suggest that, "the cycle of adoption appears to be technological advance followed by overstatement of its transformative potential for learning; then gradual adoption (or not) and an integration of technology and learning so that the use of a new technology or device seems 'natural' and disappears from view ." (Bruce and Hogan, 1998).

\section{Relating the findings to other work and theory}

The detail of our data leads us to suspect that, at present, practitioners lead two lives as users of digital technologies. One based in their personal lives where mobile and Web 2.0 technologies predominate to support and sustain personal communication, social activities and personal research and exploration of their subject/disciplines, the other based in their work, where there has been a more circumscribed use of technologies focused on business and management technologies such as word-processing, spreadsheet, presentation software, MIS and earlier Web technologies, where location of resources and information have tended to be the predominant functions reinforced by much technology training offered by providers that seeks to centralise data capture and analysis and create formal processes for the input and release of information. In the context of the JISC work on digital literacies, practitioner learning needs to develop as follows, "by digital literacy we mean those capabilities which fit an individual for living, learning and working in a digital society: for example, the skills to use digital tools to undertake academic research, writing and critical thinking; as part of personal development planning; and as a way of showcasing achievements." (JISC, 2010a). Further, JISC argue that, "courses that embed core digital skills, as well as subject specific use of technology, enable students to gain the skills and confidence they need to use digital technology not only to support their learning but also in the workplace." (ibid) Our argument here is that we are finding that practitioners are bringing their existing digital skills with them from education and previous work experience, but they are struggling to apply them for both organisational reasons e.g. security of systems, or they are not identifying uses for their personal technologies in their practice e.g. texting.

What is in question, as a result of this, is the characterisation of practitioners as teachers, where, in this context they are, with their learners, engaged in situations that have been characterised by Luckin as "obuchenie" - learning and teaching - seen as a unified developmental process when learners and teachers engage with issues collectively (Luckin, 2010). Where the distinction between learning and teaching is not possible e.g. when working in subjects where there is a rapidly evolving corpus of knowledge, it is entirely possible that students will know more about some recent developments than their teachers. However, teachers bring to their work a deeper knowledge of learning and facilitating learning which they incorporate into lessons to facilitate both the learning of their students and their own learning and professional development. In Mitra's and Dangwal's (2010) terminology such situations become self-organising mediated environments (SOMEs), where learning is stimulated and sustained by the facilitation skills of the mediator. Work by Wesch (2011) in the USA is exploring the possibilities of incorporating student contributions into courses at every level from planning to assessment and 
preparing claims for accreditation. To their knowledge of learning and facilitation of learning we are detecting, in our recent study, that practitioners, who are confident users of technology, are bringing a set of further skills and knowledge, which relates to the use of the affordances of technology to support learning. These are unlikely to have been the focus of the digital skills brought into providers by students who are, perhaps, more adept at using technology to obtain resources for learning than creating contexts for learning.

Cochrane (2010a) and his colleagues at UNITEC in Auckland, New Zealand have recognised that technology use can be central to developing the degree in design they are engaged in, but that students and staff are often in need of support and facilitation in relation to developing their work with technology. Cochrane's work has taken a pedagogical model derived from the work developed by the Learner Generated Contexts Group (Luckin et al., 2010) to engage students in teacher-led activities in Year 1 of the degree, through negotiated activity focused on androgogic practice in Year 2 towards studentcentered activities and learning in Year 3 supported by technology stewards (Wenger et al., 2010) whose role is to help teachers and students develop their use of technology to meet personal and group needs and appropriate 'digital habitats'. This work has been developed further in a more recent publication (Cochrane, 2010b) where he talks of creating, "intentional communities of practice." This work shows a practical application of a theoretical model derived from 'learner-generated contexts' and links to the work of Haythornthwaite, who has been developing a model of learning through networks and communities, which Haythornthwaite (2010b) sees as enabling the development of learning showing the following characteristics:

\begin{tabular}{|l|l|}
\hline Type of learning & Instances \\
\hline As an outcome of relations & $\begin{array}{l}\text { A community holds a knowledge of its history, and } \\
\text { information resources for dealing with new situations }\end{array}$ \\
\hline In spaces & $\begin{array}{l}\text { Affinity spaces (Gee), third places (Oldenburg), geo- } \\
\text { community spaces (libraries, community centres, churches), } \\
\text { Online learning communities }\end{array}$ \\
\hline As a relation that connects people & $\begin{array}{l}\text { A student learns from a teacher; students learn together } \\
\text { from a teacher; novices learn from each other }\end{array}$ \\
\hline As production as well as consumption & $\begin{array}{l}\text { An individual contributes content to a discussion, wiki, } \\
\text { collaborative artwork }\end{array}$ \\
\hline
\end{tabular}

The key to learning, in this model, is the development of networks to develop both informal communications such as single issue groups in Facebook and more involved and structured communications involved in professional or occupational networks with greater commitment being required in these latter cases, which may include the acquisition of the experience as well as knowledge, which is seen as the essential component of mastery by Sennett and others (Sennett, 2008). From our perspective, learning programmes developed using the Web, and other communication technologies, 
move from being the creations of closed expert groups to becoming more open to co-creation, participative learning, and to review. Potentially this allows for both the provision of more contemporary information and also enables knowledge development to promote and support learning in the future. This is similar to Castells' (2010, p.135) concept of "the creative audience" where communicative subjects, "integrate various modes and channels of communication in their practice and in their interaction with each other."

We could then argue that the 'digital practitioner' is, in part, the 'communicative practitioner' whose focus has become the initiation, support and facilitation of learning and whose expertise resides in both their subject knowledge and their ability to use technology and develop technology use in their students that opens out the 'ecology of knowledge and learning' and creates contexts to generate 'obuchenie' where learning and teaching can become fused in collaboration. We have pointers to this, in the data emerging from the LSIS study we have reported here, showing that many practitioners are open to the possibilities opened up for their practice by digital technologies as well as contributing to the utilisation and development of those same technologies.

We referred to the JISC-funded project LLiDA which looked to explore:

The evidence of change in the contexts of learning, including the nature of work, knowledge, social life and citizenship, communications media and other technologies

Review current responses to these challenges from the further and higher education sectors, in terms of:

0 The kinds of capabilities valued, taught for and assessed

$0 \quad$ The ways in which capabilities are supported ('provision')

0 The value placed on staff and student 'literacies of the digital'

0 Collect original data concerning current practice in literacies provision in UK FE and HE, including 15 institutional audits and over 40 examples of forward thinking practice (JISC, 2010b)

While we would not presume to comment on the change in contexts in learning covered in detail in the final report of this project, we feel that the study reported here adds to this picture in terms of identifying practitioner feelings about their own capabilities, the provision they are engaged in and the value they place on both generic and specific 'literacies of the digital' and the contexts in which they are deployed in their professional practice. We see these findings as supplementing the data gathered for LLiDA. What emerges from this work and other recent research is a richer picture of capability, provision and values that reinforces the messages of LLiDA, the findings of Jephcote, Salisbury and Rees (2008) and the analyses emerging from the activities of the 'Working Lives' Project in Wales concerning the 'ethic of care' for learners and changes in practice influenced by digital technology.

\section{The future - summary and issues}

We now have evidence to support the following:

Confidence is the critical measurement in the effective use of technology

Teachers who are confident in using technology in their lives are curious about how that use can transfer into their teaching practice

A level of confidence in confronting technology to use in teaching is more important than the level of knowledge about the software 
It is important to capture how people feel about 'technology in action' rather than what technology processes they know as this allows learning processes to be highlighted.

This is what we now believe that has an impact on what national agencies such LSIS, JISC and IfL do. Again, we believe we have the evidence for this:

Technology intervention in learning is fragmenting and is supporting highly individualised patterns of use. The common factor that holds it together is good teaching and learning and not uniform use of large centralised technology hosted by the employer.

Training should be aimed always at the application of technology in teaching rather than reviewing everything that the technology can do in abstract.

When it comes to expert help, teachers come to technology with curiosity to see how it might help teaching and learning rather than being passive and waiting to be directed how to use it.

There is no one way to use technology. Best practice is redundant. Good practice in a given circumstance replaces it

Impact of technology is the degree to which it is invisible in teaching and learning.

e-confidence and e-maturity are the same thing and one is a measurement of the other.

We think the following now needs to be done across the sector:

The means to assess the development of teachers is to characterise the higher level thinking skills they demonstrate in practise. Through this, any training or reflective thinking undertaken can be measured to a central common standard based on thinking skills.

Teacher exchange by subject specialism across colleges is now easily accommodated through technology as the single most important way of influencing change in using technology (amongst other things) yet it is not happening effectively

REfLECT, the IfL reflective tool, which uses an adapted e-portfolio technology, is emerging as a remarkable opportunity for teachers to capture the meta-skills through the use of tags and demonstrate individual development in a manner not yet being done

REfLECT can inform both the peer review requirements of Continuing Professional Development (IfL) as well as Employer requirements for staff development and annual appraisal. A portfolio based approach accommodates the changing landscape for capturing development.

We are, therefore, challenging JISC, the IfL, LSIS and college staff development managers here with the need for a fresh approach, in the light of the developing use of technology generally. We look forward to engaging in the discussions on further research into the nature of digital practice in learning and teaching and how this will change professional and subject knowledge in the changing contexts of the near future.

We intend to continue the work described above, which seeks to generate further data to give more representative samples in adult and work-based learning contexts and to explore how recent research and theoretical work might impact on practice and our own exploration of the issues in this paper. Through LSIS the data described here, will be made available, in suitably anonymised form, to the research community as well as making the method available for use in other self-assessment and research activity. With 350,000 
words of free text available for analysis, we will be looking to continue our exploration of this rich resource and making this available for other researchers to use with other forms of analysis.

\section{References}

Bruce, B.C., and Hogan, M.P. (1998) The Disappearance of Technology: Toward an Ecological Model of Literacy. In: Reinking, D., McKenna, M., Labbo, L., and Kieffer, R. (eds.) Handbook of Literacy and Technology: Transformations in a Post-Typographical World. pp. 269-8. Hillsdale. NJ: Erlbaum.

Castells, M. (2010) Communication Power. Oxford: University Press.

Cochrane, T.D. (2010a) Exploring Mobile Learning Success Factors. ALT-J - Research in learning technology, 18 (2), pp. 133-148.

Cochrane, T.D. (2010b) Beyond the Yellow Brick Road: Mobile Web 2.0 Informing a New Institutional ELearning Strategy. ALT-J, 18 (3), pp. 221-231. London: Taylor and Francis.

Garnett, F., and Ecclesfield, N. 2011. Towards a Framework for Co-Creating Open Scholarship. Proceedings of ALT-C, 2011. ALT, Oxford.

Haythornthwaite, C. 2010a. New Forms of Doctorate. Leverhulme Trust Public Lectures Series. [Online]. Available at: http://newdoctorates.blogspot.com/2009/10/leverhulme-trust-public-lectures.html Operative on 31 July 2011.

Haythornthwaite, C. 2010b. Learning Networks. Presentation to Open University, July 2010. [Online]. Available at: www.open.ac.uk/blogs/terg/wp-content/uploads/2010/07/haythornthwaite.pdf Operative on 31 July 2011.

Haythornthwaite, C., and Andrews, R. (2011) E-learning Theory and Practice. London: Sage.

Jephcote, M., Salisbury, J., and Rees, G. (2008) Being a Teacher in Further Education in Changing Times. Research in Post-Compulsory Education, 13 (2), pp. 163-172.

JISC. 2010a. Developing Digital Literacies. [Online]. Available at: www.jisc.ac.uk/whatwedo/programmes/ elearning/developingdigitalliteracies.aspx Operative on 31 October 2011.

JISC. 2010b. Learning Literacies in a Digital Age (LLiDA). [Online]. Available at: www.jisc.ac.uk/whatwedo/ projects/elearningllida.aspx Operative on 31 October 2011.

Luckin, R., Clark, W., Garnett, F., and Whitworth, A. (2010) Learner Generated Contexts: A Framework to Support the Effective Use of Technology for Learning. In: Lee, M., Sturt, C., and McLoughlin, C. (eds.). Web 2.0-based e-learning: applying social informatics for tertiary education. Sydney: IGI Global.

Mitra, S., and Dangwal, R. (2010) Limits to Self-Organising Systems of Learning - the Kalikuppam

Experiment. British Journal of Educational Technology, 41 (5), pp. 672-688.

Morris, D., and Ecclesfield, N. (2011) A New Computer-Aided Technique for Qualitative Document Analysis. International Journal of Research and Method in Education, 34 (3), pp. 241-254.

Petty, G. (2006) Evidence Based Teaching. London: Nelson Thornes,

Rossett, A., and Schafer, L. (2010) Job Aids and Performance Support: Moving from Knowledge in the Classroom to Knowledge Everywhere. New York: Pfeiffer.

Sennett, R. (2008) The Craftsman. London: Allen Lane.

Wesch, M. (2011) Digital Ethnography. [Online]. Available at: www.youtube.com/user/mwesch Accessed 
Compass: The Journal of Learning and Teaching at the University of Greenwich, Issue 5, 2012 11 October 2011 
Compass: The Journal of Learning and Teaching at the University of Greenwich, Issue 5, 2012 